\title{
Anseios e devaneios: a memória social envolta ao progresso de legalização da maconha para fins medicinais no Brasil
}

\section{Josemar da Silva Junior Elias ${ }^{I}$ \\ http://orcid.org/0000-0002-5217-8447}

Bernardina Maria Juvenal Freire de Oliveira ${ }^{I I}$ http://orcid.org/0000-0002-6836-3102

Maria Nilza Rosa Barbosa ${ }^{I I I}$

http://orcid.org/0000-0002-2476-2793

${ }^{I}$ Universidade Federal da Paraíba, PB, Brasil.

Doutorando e Mestre em Ciência da Informação pelo PPGCI/UFPB.

${ }^{I I}$ Universidade Federal da Paraíba, PB, Brasil.

Professora doutora no Programa de Pós-graduação

em Ciência da Informação (PPGCI/UFPB).

III Universidade Federal da Paraíba, PB, Brasil.

Professora doutora no Programa de Pós-graduação

em Ciência da Informação (PPGCI/UFPB).

http://dx.doi.org/10.1590/1981-5344/3350

Reflete sobre o histórico da criminalização do uso da maconha abordando aspectos culturais e jurídicos, através de uma linha tênue entre a informação e a memória. Aponta alguns registros de proibição da planta, pontuando como a memória social foi construída em torno de uma atmosfera proibicionista e repressiva ao uso da droga e como isso reverberou por longos anos. Frisa como a onda de proibicionismo e repressão contribuiu para a 
construção de uma memória social preconceituosa e descriminatória. Elenca os principais avanços advindos com a chegada do século vinte e um, e os principais marcadores históricos nesta caminhada, assim como enfatiza a mudança da conjuntura social no tocante ao seu ponto de vista em relação à questão da legalização da maconha para fins medicinais, concluindo que, é necessário ainda muita luta e resistência para que os avanços sejam realizados de modo a abranger todas as camadas sociais de forma efetiva.

Palavras chave: criminalização; maconha; avanços; memória social; informação.

\section{Wonders and devanies: the social memory involved in the progress of marijuana legalization for medical purposes in Brazil}

Reflecting on the history of the criminalization of marijuana use, addressing cultural and legal aspects, through a line of information and a memory. We pointed out some banning records of the plant, scoring as a social memory, was built around an atmosphere, prohibiting and repressive to use the drug and how it reverberated for long years. It emphasizes how a wave of prohibitionism and repression contributed to the construction of a discriminatory and prejudicial social memory. And the main historical markers in this walk, as well as emphasizing a change in the social context in relation to the question of the legalization of marijuana for medical finances, concluding that it is necessary still the struggle and the resistance so that the advances are realized in form to cover all the social layers of effective form.

Keywords: criminalization; marijuana; advances; social memory; information. 


\section{Introdução}

O tema "drogas" é uma questão que permeia a sociedade desde muito tempo, e que alcança os vários estratos sociais, dos padrões mais baixos até os mais elevados. Partindo para a droga maconha - palavra usada para designar folhas, flores e sementes da planta de cânhamo da Índia -, esta foi configurada como uma droga ilícita desde o século passado, contudo nos períodos que antecederam este século a mesma consistia em uma proeminente matéria prima da economia europeia; insumo relevante para as práticas renascentistas, pois, o cânhamo era utilizado para a fabricação de telas e do papel (BARROS; PERES, 2012). Todavia no trato dado a esta temática, seja político ou social, ocorre que quase sempre os discursos são arraigados de preconceitos, crenças, medos, anseios e, o que pode ser considerado mais gravídico: certezas (BESSA, 2010). Tais certezas totalmente descontextualizadas e com a ausência de imparcialidade.

Buscando desconstruir o misticismo envolto a esta questão, bem como combater as nuances pejorativas e o caráter marginal, atribuídos à legalização da maconha para fins recreativos, medicinais ou industriais, alguns grupos promovem manifestações e buscam por meio de proposições de projetos de Leis junto ao Senado Federal, avançar neste quadro e trazer a maconha ao seu posto de legalidade como anteriormente, haja vista os inúmeros benefícios trazidos pela mesma no tocante à saúde - a fabricação do canabidiol, além disso, o fato de que com a regulação da mesma consegue-se combater ou reduzir problemas sociais, tais como, a marginalização, a violência associada ao narcotráfico, o comércio ilegal de substâncias adulteradas, os inúmeros gastos governamentais utilizados para resolver os problemas sociais gerados, e até mesmo o estímulo e fomento à pesquisas clínicas/científicas sobre os benefícios de plantas medicinais proscritas.

Neste viés, tendo em vista ser a delimitação de lícito e ilícito uma construção social, e que o período histórico condiciona as ações humanas, observa-se uma memória construída envolta a esta problemática social que, trazendo para a ambiência brasileira toma outros contornos a partir do ano de 2014 em razão de uma proposta popular de regulação para os usos recreativo, medicinal e industrial da maconha o que reverberou em discussões e pautas no Senado Federal e Câmara dos deputados nesta perspectiva de regulação (KIEPPER; ESHER, 2014). Com isso foi dado início a uma jornada, em prol especialmente do uso da cannabis, nome 
científico da maconha, para o fim medicinal, e nesse cenário, percebendose por meio de relatos, de lutas, de associações, a atmosfera memorialística de proibicionismo e repressão direcionadas à maconha estão se modificando.

O presente artigo se debruça na compreensão da memória construída em dois períodos compreendidos no processo histórico de legalização da maconha no Brasil. Primeiramente, quando dos reflexos da proeminência da Lei $11.343 / 2006$ que institui o Sistema Nacional de Políticas Públicas sobre Drogas - SISNAD; bem como prescreve medidas para prevenção do uso indevido, atenção e reinserção social de usuários e dependentes de drogas; estabelece normas para repressão à produção não autorizada e ao tráfico ilícito de drogas; define crimes e dá outras providências, sendo esta balizadora das ações políticas no contexto social e norteador dos avanços na área da ciência e da saúde.

Em segundo momento, trazer os avanços conquistados por meio da Iuta e resistência social, de uma população cada vez mais consciente dos benefícios advindos do uso medicinal da cannabis e de famílias com um vasto histórico detrauma por presenciar no seio do seu lar filhos e parentes convulsionando reiteradas vezes por dia. Desta forma, tendo como estopim a recepção por parte da Câmara de Direitos Humanos da SUG No 08/2014 em 11 de fevereiro de 2014 e, por conseguinte uma adesão de muitos brasileiros a tal sugestão pública, tais reforços se refletem em janeiro de 2017 na aprovação da maconha como erva medicinal pela Agência Nacional de Vigilância Sanitária -(ANVISA), permitindo a produção, manufatura, exportação, importação, posse ou uso da planta para fins médicos e científicos, mas sempre passando pelo crivo dos órgãos públicos.

\section{A criminalização da maconha no Brasil: os valores são invertidos e uma memória é construída}

A folha de maconha por muito tempo foi insumo das dinâmicas sociais e econômicas na Europa, desde a época paleolítica - em tal período, ainda popularmente chamada de cânhamo, - sendo ela considerada um dos principais produtos agrícolas daquela região. Desta forma, neste primeiro cenário a utilização da planta é um componente essencial à produção de artefatos que vão auxiliar os indivíduos em atividades cotidianas de trabalho e lazer, como é o caso do período da Renascença:

Prova de sua grande influência na mudança de mentalidades é que, além das páginas de papel de cânhamo dos primeiros livros impressos, artistas pintavam em telas feitas com suas fibras. Tanto 
que a palavra Canvas, usada em várias línguas para designar "tela", é uma corruptela holandesa do latim 'cannabis': daí dizer-se 'oiloncanvas' (óleo sobre tela)' (BARROS; PERES, 2012, p. 2).

Ressalta-se que muito antes disso as civilizações antigas já se utilizavam de plantas, hoje proscritas, para finalidades terapêuticas, medicinais ou de cunho religioso, como é o caso dos povos Sumérios quando descobertas as tábuas de argila na mesopotâmia que constavam de informações acerca do cultivo da papoula e do processo de preparação do ópio - substância extraída em forma de suco da papoula - e que os seus benefícios terapêuticos eram reconhecidos por toda a Pérsia e Egito cerca de 1.500 A.C. Os romanos já faziam uso do ópio com finalidades medicinais; os Assírios faziam uso do cânhamo para estabelecer rituais religiosos de adoração a seus Deuses (AMUY, 2005; ISRAEL-PINTO, 2012).

No período das descobertas, Colombo traz sementes de maconha às Américas haja vista ser material fundamental para a fabricação das velas dosbarcos. Sobre esta perspectiva histórica do uso de plantas medicinais Bessa (2010, p. 633) relata que "os índios brasileiros consumiam uma bebida alcoólica derivada da fermentação da mandioca - o cauim. Esse uso era coletivo, em rituais nos quais todos participavam e bebiam como forma de congraçamento da tribo. Não havia o consumo individual e nem cotidiano".

O uso da substância era feito de forma coletiva ou individual buscando cumprir uma função cultural em um contexto social. Essa conjuntura de aceitabilidade e pulverização social foi sendo alternada com o decorrer dos tempos, isso em face ao período mercantilista que promoveu a transformação da droga em mercadorias, provocando uma desconstrução de sua finalidade social. Neste sentido, destacam-se as considerações de Bessa (2010, p. 634) ao afirmar que nesta fase elementos como "[...], por exemplo, o vinho e outras bebidas, ou o tabaco comercializado nas colônias americanas para a Europa, ou por outras metrópoles com suas respectivas colônias", fizeram parte deste cenário.Todavia esta conjuntura vem a se intensificar com mais rigor com o advento do capitalismo, que fez com que as drogas se tornassem mercadorias de alto valor, invertendo o seu papel simbólico e de utilidade coletiva para um uso individual e sem função social (BESSA, 2010).

No contexto brasileiro é "[...] indiscutível que as raízes da criminalização da maconha estão ligadas à diáspora africana" (BARROS; PERES, 2012, p. 6), por volta do século XIX, em razão da psiquiatria Iombrosiana ter chegado ao Brasil, o uso da maconha era associada aos escravos com contornos criminalizantes, haja vista estes terem trazido a 
planta para o Brasil por fazerem uso dela em seus rituais religiosos, assim como ter o hábito de consumo diário, "prova de que esse hábito foi trazido da África pelos escravos é que uma das mais conhecidas denominações da maconha era 'fumo de Angola'"' (BARROS; PERES, 2012, p.11).

Lombroso (1835-1909) era criminologista e suas teorias buscavam relacionar traços físicos das pessoas a seus aspectos mentais e de comportamento. Inspirando-se em estudos genéticos e evolutivos no final do século XIX, afirmava que os criminosos possuíam evidências físicas de um "atavismo" (reaparição de características de ascendentes distantes) hereditário, reminiscente de estágios mais primitivos da evolução humana, anomalias em termos de formas do crânio e mandíbula, face e outras partes do corpo. Posteriormente, estas associações foram consideradas inconsistentes ou inexistentes (BARROS; PERES, 2012). Neste período verificam-se os primeiros indícios de criminalização da maconha, contudo acompanhado de discursos racistas e segregadores, mesmo tendo sido declarada a abolição da escravatura, como se não bastasse, o histórico de sofrimento e preconceitos sofridos pela comunidade negra.

Antecedendo esta época da entrada do pensamento lombrosiano no Brasil, um dispositivo jurídico foi criado e restava por acentuar ainda mais a criminalização da maconha e sua associação aos indivíduos negros. Em 04 de outubro de 1830 a Câmara Municipal da cidade do Rio de Janeiro (RJ) atribuía pena ao uso e venda do 'pito do pango' - termo dado a maconha - em seu parágrafo sétimo da postura que versava sobre a venda de gêneros e remédios e sobre boticários afirmava que:

É proibida a venda e o uso do pito do pango, bem como a conservação dele em casas públicas. Os contraventores serão multados, a saber: o vendedor em 20\$000, e os escravos e mais pessoas, que dele usarem, em três dias de cadeia. "o vendedor [multado] em 20\$000, e os escravos, e mais pessoas que dele usarem, em 3 dias de cadeia (DÓRIA, 1958, p.17).

Todavia "uma legislação proibitiva mais abrangente - de caráter nacional - sobre a maconha só apareceria mais de cem anos depois, através da inclusão da planta na lista de substâncias proscritas em 1932" (SAAD, 2013, p. 3). Tal ação governamental decretou o proibicionismo da planta em nível nacional e com isso acentuou o caráter repressivo e marginal depositados no uso do cânhamo desde a escravatura, por uma população que buscava um padrão social de higienização e branqueamento, de viés positivista, revestido de práticas moralistas, religiosas e políticas fechavam os olhos para o contexto cultural das sociedades e suas relações com a planta. 
Os esforços em marginalizar o uso da maconha só se intensificaram até chegar mais fortemente aos tempos modernos promovendo uma verdadeira "Guerra às drogas" (KARAM, 2013), hoje marginalizando não só negros, mas todos que dela fizerem uso ilegalmente. Um dispositivo legal mais recente que Lei $11.343 / 2006$ que institui o Sistema Nacional de Políticas Públicas sobre Drogas - (SISNAD), bem como prescreve medidas para prevenção do uso indevido, atenção e reinserção social de usuários e dependentes de drogas; estabelece normas para repressão à produção não autorizada e ao tráfico ilícito de drogas; define crimes e dá outras providências. Em análise a tal dispositivo verifica-se que mais da metade dos artigos nele elencados são de teor repressivo e proibitivo, e apenas 23 tratam do direito do usuário de drogas - prevenção, atenção e reinserção social. Neste sentido, valem as considerações da juíza Maria Lúcia Karam (2009, p. 1) ao discorrer sobre a conjuntura proibicionista:

A política criminalizadora de condutas relacionadas à produção, à distribuição e ao consumo de determinadas substâncias psicoativas e matérias primas para sua produção, ocultando a identidade essencial em todas as substâncias psicoativas e a artificialidade da distinção entre drogas lícitas e ilícitas, é, hoje, a mais organizada, mais sistemática, mais estruturada, mais ampla e mais danosa forma de manifestação do proibicionismo a nível mundial.

Seguindo esta linha de entendimento, e adicionando o acarretamento de problemas sociais atrelados a tal propositura,Kiepper e Esher (2014, p. 1) afirmam que:

O modelo proibicionista de combate às drogas demonstra um esgotamento que pode ser visto na violência associada ao narcotráfico, no comércio ilegal de substâncias adulteradas, nas receitas fiscais perdidas, no desperdício de recursos públicos, no desvio da atenção dos problemas reais da sociedade para uma falsa solução e na ausência de pesquisas clínicas sobre a eficácia e efetividade das plantas medicina is proscritas.

Nesta perspectiva, surge como preocupação o imaginário construído pelas novas gerações, que em razão da ausência de muitos estudos direcionados a esta temática e a problemática envolta a ela, podem construir seus referenciais de memória a partir do negativismo do proibicionismo, da marginalização instaurada e da repressão, excluindo assim as benfeitorias e as construções históricas realizadas em cima do uso da maconha. Na perspectiva da memória, sabe-se que esta é uma ressignificação do passado, a possibilidade de trazer à tona, fatos que passaram, com o olhar do presente, uma maneira de agregar a realidade 
de hoje ao que foi vivenciado anteriormente. Diante do quadro imposto e construído pela elite frente a utilização da planta queda-se em uma memória traumática e desprovida dos verdadeiros entornos sociais que circundaram esta temática.

Desta forma, grupos sociais de militantes e em formações associativistas buscam ressignificar as raízes históricas da cannabis, reafirmando o seu potencial medicinal e buscando a sua regulação para fins, especialmente medicinais, como forma de se reduzir as problemáticas sociais vigentes, como o contrabando, a violência, e as doenças que assolam parte dos brasileiros. "Aqui, no Brasil, ao levarmos em consideração as mudanças nos níveis judicial e legal, é fundamental ressaltar que as Marchas da Maconha influenciaram estes avanços" (BARROS; PERES, 2012, p.18). Desta forma desde 2014 até os dias atuais, o uso da maconha vem ganhando novos contornos e agregando mais sensibilidade no contexto social, especialmente com vistas aos benefícios que podem ser promovidos às famílias de crianças e adultos, ao minimizarem um quadro patológico, com a sua utilização medicinal. Este cenário promove cada vezmais debates e discussões em torno da descriminalização e legalização.

\section{Construções e desconstruções memorialísticas frente a uma política de proibicionismo}

Frente à repercussão gerada em torno da cannabisobserva-se que a conotação preconceituosa e marginalizada atribuída ao uso dela perpetuou por um grande período de tempo, assolando principalmente e primeiramente a comunidade negra e em seguida isso se estende a qualquer indivíduo que dela faz uso dela, de maneira considerada "ilegal" (SAAD, 2013). Sendo assim, as memórias em relação a tal questão são construídas bebendo da fonte de discursos e histórias de preconceito, racismo, vandalismo, marginalização e crime, o que restou por reverberar de 1830 até os dias atuais, provocando a desconstrução de uma prática cultural de determinado grupo social.

Diante disto destaca-se que a priori identificada uma parcela da sociedade caracterizada como "elite", em face às relações de poder existentes, como proponente a essa conjuntura de marginalização, que revestidos do sentimento de não pertencimento e superioridade a grupos sociais buscaram por tempos silenciar e obscurecer uma prática cultural de um grupo, desta forma restou por fomentar uma construção memorialística de sofrimentos arraigada de entornos criminalizantes e repressivos. Nesta perspectiva cumpre pontuar o que Azevedo Netto (2007, p. 8) traz acerca da noção de memória que: "[...] está transpassada por um universo simbólico do mais significativo mediante 
um processo de representação no qual são criados referentes para sua cristalização nas consciências, quer individuais quer coletiva, aproximando-a, em muito, da noção de identidade".

O conceito de memória sempre esteve conexo à sociedade tanto em sua abrangência coletiva como individual, "[...] conjugando e nutrindo uma relação existencial sobre si, sobre o outro e sobre nós, em uma realidade de alteridade e significado que se estrutura em nosso habitus, configurado no cotidiano" (SILVA; OLIVEIRA, 2014, p. 136). A expressãohabitus foi cunhada por Bourdieu (1983), e define-se como uma noção mediadora entre a estrutura e $o$ agente em que se procura incorporar os graus de liberdade e determinismo presentes na ação dos agentes sociais. O nosso habitusconstrói-se no processo de socialização: um processo inacabado porque nunca se extingue no decorrer da vida, mas não uniforme porque a socialização tem múltiplos graus e matizes.

Neste viés a representatividade quase sempre atribuída à planta era de que amesma, configurava-se em "algo venenoso", entorpecente e enlouquecedor, e aos que faziam seu uso, quase sempre associados a vândalos, infratores da lei, viciados e marginais. Nesta vertente há de se considerar que "a memória é a identidade em ação, mas ela pode, ao contrário, ameaçar, perturbar e mesmo arruinar o sentimento de identidade" (CANDAU, 2016, p. 18), o que se visualiza bem no caso da cannabis no Brasil.

Pollak (1992) fornece uma conceituação acerca de memória social pontuando seu laço estrito com a identidade, destaca a memória em todas as áreas da vida como um fenômeno produzido social e individualmente, e que ao escrever acerca de memória herdada, constata-se a relação fenomenológica intensa existente entre ela e o sentimento de identidade. Trocando em miúdos, a relação entre memória e identidade configura-se ao passo que estas últimas se fundam como patrimônio de significados, que fazem uma ponte até a criação de uma memória e de um discurso que fundamente a noção de pertencimento.

Corroborando com tal interpretação, tem-se o entendimento de Candau (2016), que associa a identidade a como os indivíduos tomam para si determinadas conjecturas do passado. Ele diz: "se a memória é geradora do sentimento de identidade, no sentido de que participa de sua construção, essa identidade, por outro lado, molda predisposições que vão levar os 'indivíduos' a 'incorporar certos aspectos particulares do passado a fazer escolhas memoriais"(CANDAU, 2016, p.19).

Desta forma observam-se os esforços em repreender o uso de uma substância que possuía inúmeros benefícios, refletindo e reforçando tal entendimento, identifica-se que a imprensa foi forte mecanismo de contribuição para com a marginalização da maconha, e como isso alimentou a construção memorial de grupos sociais viventes à época, 
Anseios e devaneios: a memória social envolta ao progresso de legalização da maconha para fins medicinais no Brasil
Josemar da Silva Junior Elias; Bernardina Maria Juvenal Freire de Oliveira; Maria Nilza Rosa Barbosa

conforme se apresenta nas ilustrações a seguir: manchetes que deterioram a erva criminalizam escravos usuários, enaltecem a sua característica alucinógena e que a posicionam como um verdadeiro "mal" para a sociedade promovendo um verdadeiro terror em torno do seu uso.

Figura1-Reportagem do jornal "O GLOBO" em 1956.

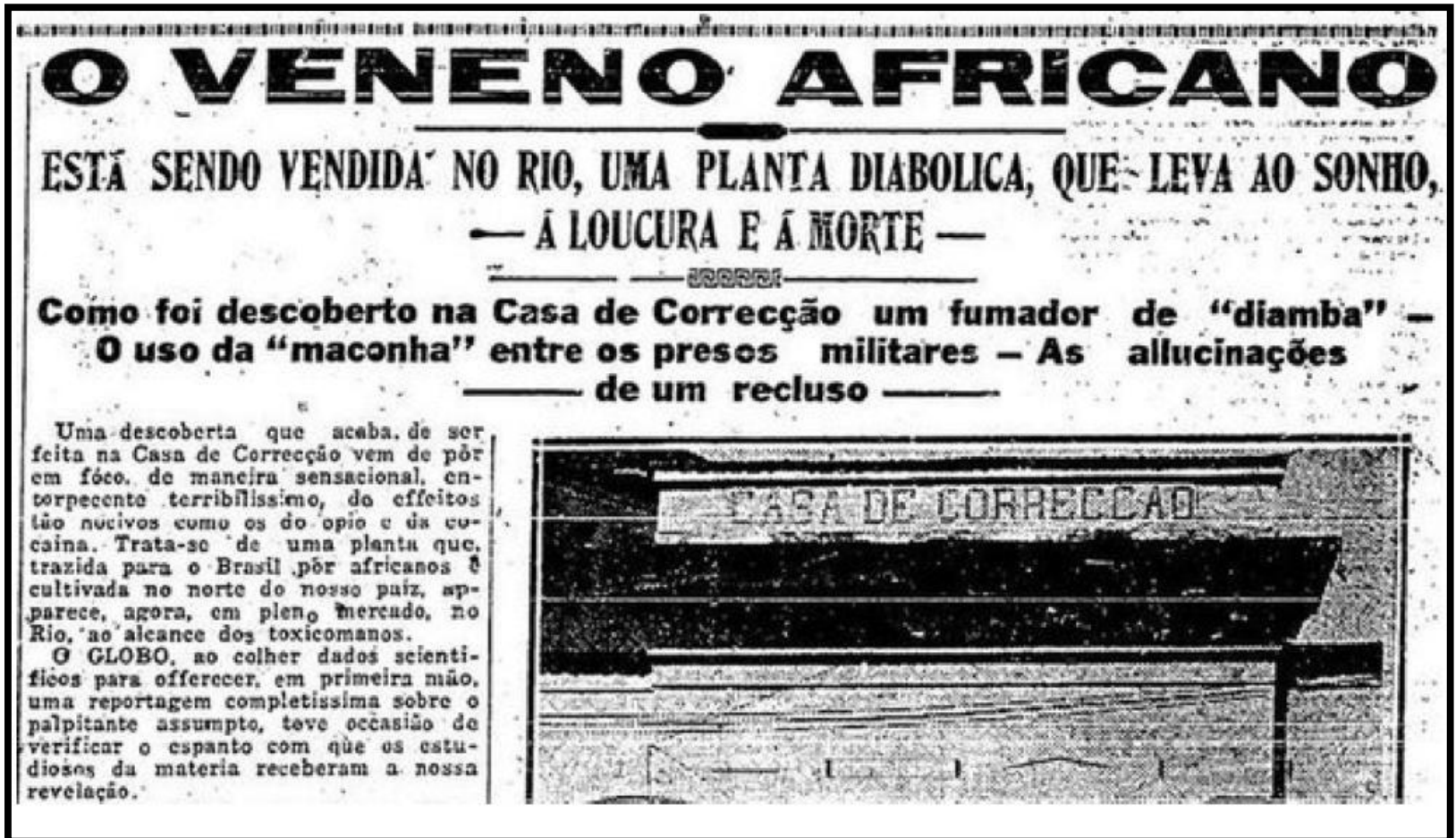

Fonte: https://www.smokebuddies.com.br/a-maconha-no-brasil-uma-breve-historia-do-legal-aolegal/

Figura2-Recortes jornalísticos

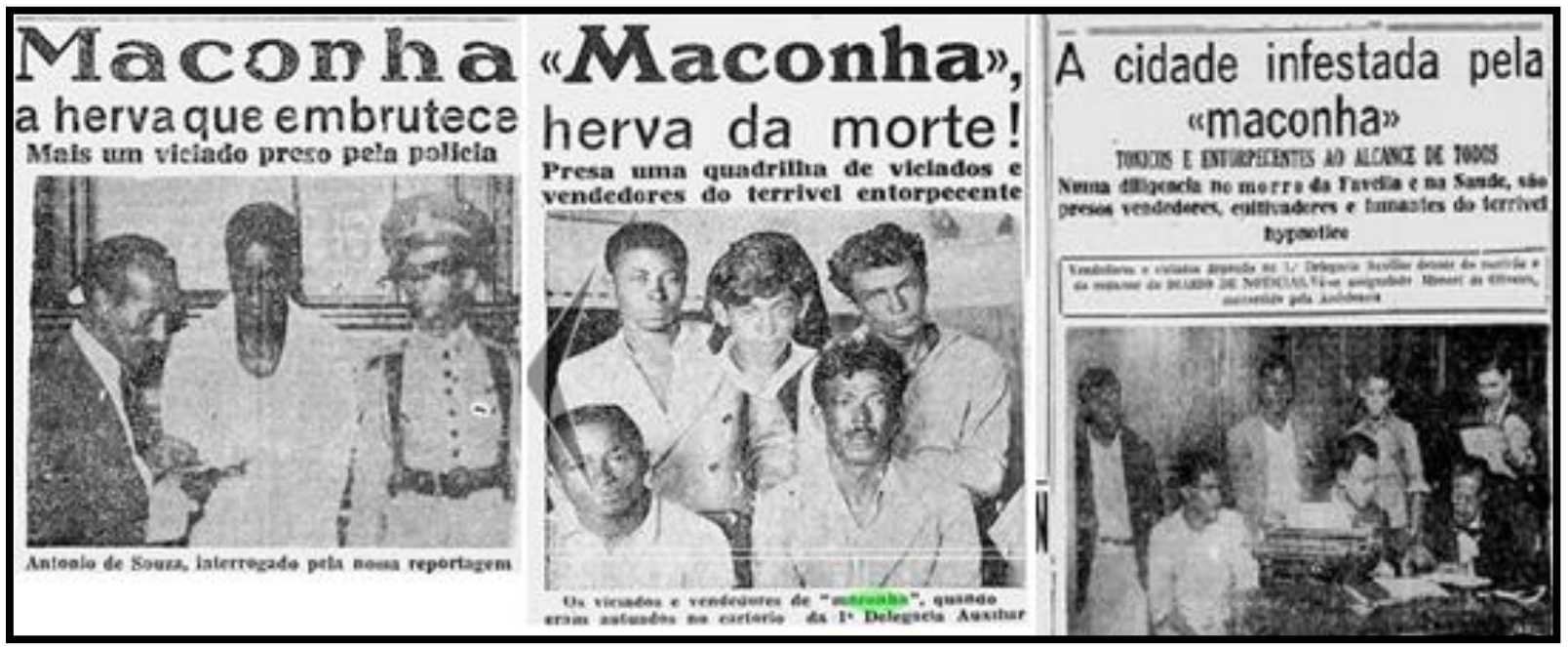

Fonte: KORYTOWSKI, 2016. 
Figura3-Anúncio de fuga de escravo "fumador de pango" no Diário do Rio de Janeiro de 2 de agosto de 1833.

84 Fugio no dia $1 \mathrm{I}$ le Inneiro de 18.33, hum molegue de nonse Narcizo, nacian Augola. ilusle de 14 ansos, cara redonda, cor bem preta, aignaes de bexigas, olhos redondos, e averubelbados, baixo, reling:ndo, atsclar acispariogudo, permas lium tunto curvä́s para dentro. pés grandes, pizando mal, levou calça le. brim, jaçueta de quadrados azuis, e brance, camiza de brin, signal no alto da cabeca de carregrar, jí tivi aprentiz de Carpinteire, e agora vondia agullias, e alfinetes, bebe, jora, he cipheira, e granste fumador de pango, lasse por escruvos te varias pessous, mas pertesice a $\mathrm{D}$. Maria Clara de Incerila, on a sea tilino loño Maria de Lacerda; quem o levat, on Hor noticia na rua sletras do Carnu n. 36 , sérá bem gratifacado.

Fonte:KORYTOWSKI, 2016.

Diehl (2002) considera a memória como uma representação das experiências vividas pelos homens, acentuando, em tal contexto, a sua dimensão social. Frente a isso, consegue-se extrair que embora a memória esteja sempre vinculada a um sujeito ou a um grupo, ela sempre será subordinada a um contexto cultural firmado num espaço temporal. Desta forma, em atenção aos recortes jornalísticos trazidos é importante que não se fixe a este imaginário, pensando esta memória como algo estático, "[...] ela deve ser antes compreendida como 'território', como espaço vivo, político e simbólico no qual se lida com as lembranças e com os esquecimentos que restituem o Ser Social a cada instante" (BARROS, 2009, p. 37).

Partindo deste pressuposto, e sabendo que "[...] a memória é enraizada a uma retórica de profundo questionamento acerca daquilo que podemos revitalizar ou rememorar" (BARROS, 2009, p. 37), é de se considerar que a sociedade começa a rever e questionar as imposições políticas em relação ao uso e caráter criminal da erva, desta forma observa-se a alternância deste quadro de repressão no século XXI com os reconhecimentos na esfera social e judicial, haja vista uma sociedade mais sensibilizada com o trajeto de lutas de famílias que tem na legalização uma esperança de saúde melhor para seus entes. Os grupos sociais, que 
militam pela desnaturalização deste discurso imposto e arraigado no seio social buscam resgatar os valores culturais da maconha. E nesta perspectiva observamos uma nova memória sendo construída, livre de preconceitos ou racismos, diferindo da anterior que ora foi exposta.

\section{Século XXI, uma era de avanços?}

Muito embora os avanços na esfera científica e tecnológica estarem impactando de forma substancial as dinâmicas sociais, provocando mudanças e quebrando barreiras geográficas, ainda assim não são suficientes para resolução dos problemas sociais e econômicos (KARAM, 2013). A marginalização, pobreza, a saúde escassa, dentre outros fatores sociais continuam sendo potencializados, e desta forma tal conjuntura resta por refletir na problemática das drogas, que embora haja uma política pautada na intervenção do Estado junto a tal questão, criminalizando o uso, porte e comércio, assim como ações repressivas a quem dela faz uso, não conseguem reduzir significativamente os problemas sociais advindos dela, pelo contrário, o tráfico de entorpecentes é um indicador crescente disto.

[...] no caso recente da maconha, no Brasil tem sido comum utilizar-se uma retórica na qual o uso da substância estaria relacionado com a liberdade e os direitos do cidadão. Já o cigarro inspira outro tipo de retórica, que busca estimular uma ação estatal para controlar o abuso das companhias produtoras. A retórica pode mudar de país para país, de acordo com o momento histórico (LARANJEIRA, 2010, p.622).

Como reação a onda proibicionista e repressiva ao uso da cannabis, muitas pessoas se sensibilizaram e solidarizaram com o depoimento de famílias que vivenciam diariamente a realidade de doenças tais como a epilepsia, a esclerose múltipla e os portadores de dores crônicas, que tratadas com os derivados da maconha têm consideráveis melhorias. Compreendendo a importância do fortalecimento social em prol dessa sensibilização, recordemos Bauman (2001), ao afirmar que somos responsáveis pelo outro, estando atento a isto ou não, desejando ou não, torcendo positivamente ou indo contra, pela simples razão de que, em nosso mundo globalizado, tudo o que fazemos (ou deixamos de fazer) tem impacto na vida de todo mundo e tudo o que as pessoas fazem (ou se privam de fazer) acaba afetando nossas vidas.

A cannabis tem cerca de 400 compostos químicos, assim como 60 canabinóides que possuem princípios ativos singulares, e dentro desta gama de componentes, dois são sublinhados: o tetrahidrocanabinol (THC) e o canabidiol (CDB). Todavia em vista as propriedades medicinais e 
terapêuticas os direcionamentos positivos para o canabidiol são mais acentuados, haja vista, esse não possuir o caráter de alucinógeno, diferentemente do tetrahidrocanabinol que se configura como a principal substância psicoativa da planta, que proporcionando alucinações e caso haja um uso desregrado pode ocasionar dependência. (MONTEIRO, 2014).

De acordo com Grinspoon (2005 apud KIEPPER; ESCHER, 2012, p. 2), a maconha pode ser utilizada de forma paliativa no tratamento de:

[...] náuseas e vômitos severos da quimioterapia do câncer; epilepsia; esclerose múltipla; glaucoma; dor e espasmo de paraplegia e tetraplegia; dor crônica; HIV/AIDS; enxaqueca; doenças reumáticas (osteoartrite e espondilite anquilosante); cólicas menstruais; síndrome pré-menstrual; dores do parto; doença de Crohn; colite ulcerativa; dor do membro fantasma; hiperemese gravídica e depressão.

Bucaresky (2014 apudJESUS et al, 2017, p. 3-4) pontua que muitas pesquisas estão sendo realizadas no direcionamento das benfeitorias medicinais do uso da maconha:

Segundo o Seminário da Câmara dos Deputados Comissão de Seguridade Social e Família sobre o uso medicinal do canabidiol, em consulta a base de dados da PUBMED (US National Library of Medicine National Institutes of Health), identificou-se em torno de 500 artigos científicos que fazem referência a efeitos terapêuticos do canabidiol como: anticonvulsivante, alzheimer, esquizofrenia, doença de Parkinson, esclerose múltipla, transtorno do pânico, HIV, câncer, glaucoma, asma, epilepsia, entre outros.

Desta forma, avanços jurídicos no sentido de reconhecer o potencial medicinal da planta são identificados mais especificamente do ano de 2014 aos dias atuais, pois "embora a planta não tenha a propriedade de curar essas doenças, seus componentes têm se mostrado efetivos para tornar melhor a qualidade de vida dos pacientes" (JESUS et al, 2017, p. 4).

Aliado a isso as reivindicações sociais que se materializam em associações como aAssociação Brasileira de apoio a Cannabis Esperança(ABRACE)e a Liga Canábica, ambas situadas na Paraíba, destaca-se. No caso da primeira, houve a conquista judicial na autorização do cultivo de maconha para fins medicinais, tal associação é responsável pela fabricação do óleo da maconha a base de canabidiol e distribui de forma gratuita a pacientes que sofrem de convulsões, todo o controle com vistas 
a evitar uma propagação indevida é feito pela associação mediante cadastro de todos os beneficiários.

Figura4- Marcha da Maconha em São Paulo - SP

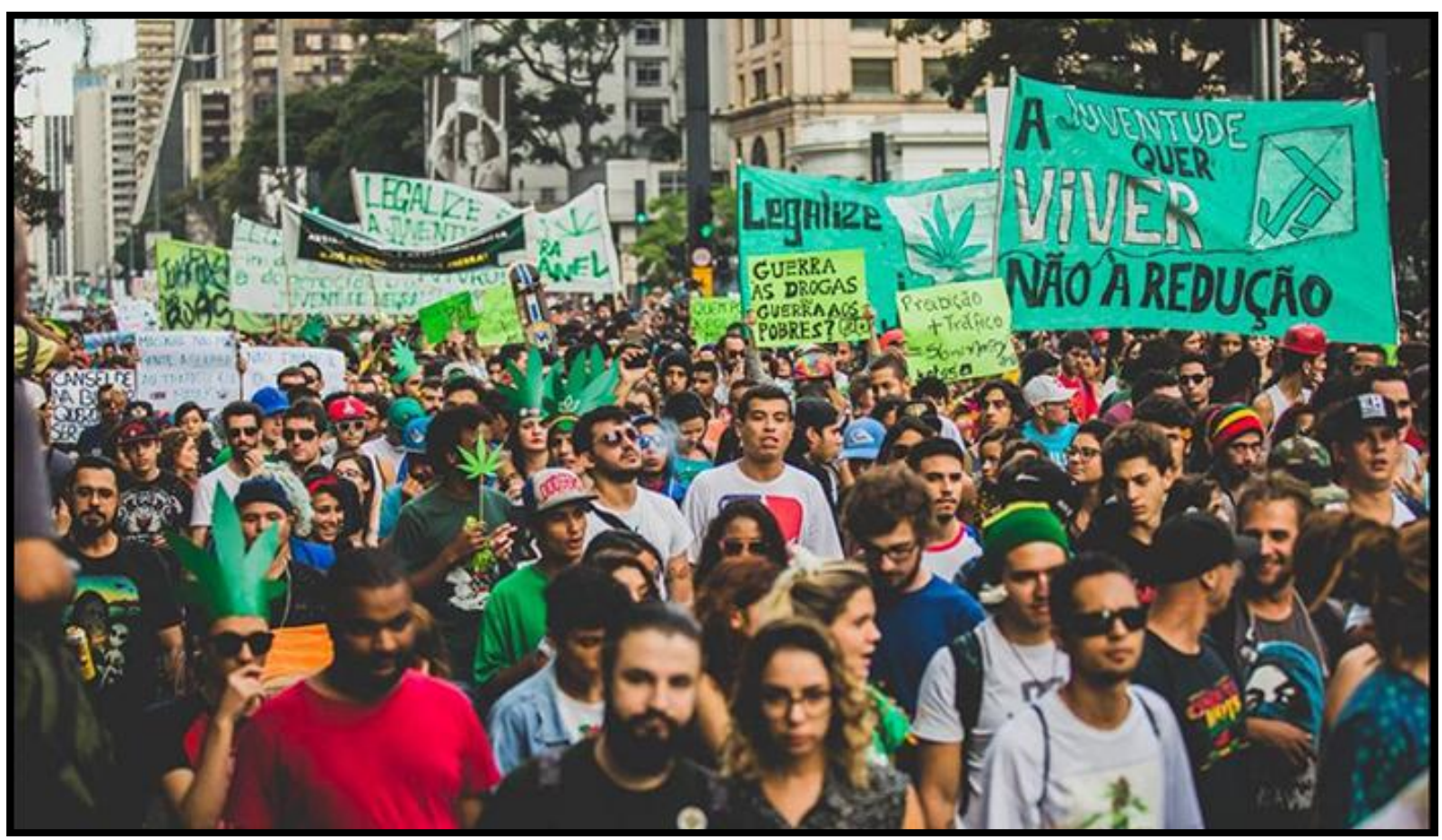

Fonte: SUDRÉ, 2016.

Outro marcador importante nesta perspectiva é a marcha da maconha, que foi aprovada por unanimidade pelo Supremo Tribunal Federal - STF atendendo à Arguição de Descumprimento de Preceito Fundamental (ADPF) no 187/DF. De acordo com o ministro Celso de Mello em consideração a tal aprovação, ele alega que tal evento é um movimento social espontâneo que reivindica, por meio da livre manifestação do pensamento, "a possibilidade da discussão democrática do modelo proibicionista (do consumo de drogas) e dos efeitos que (esse modelo) produziu em termos de incremento da violência", divulgado na Imprensa em 2011. Sendo assim, o evento vem realizando-se desde 2008 de maneira anual, porém só a partir de 2011 com a sua legitimidade o caráter proibicionista e de apologia ao uso de drogas foi quebrado. 0 pontapé para os avanços nesta seara se deu com a SUG No 08/2014 em 11 de fevereiro de 2014, recepcionada pela Câmara de Direitos Humanos de relatoria do Senador Cristovam Buarque (PDT/DF).

A repercussão da SUG no 8/2014 impulsionou também a apresentação, na Câmara dos Deputados, de dois projetos de lei que autorizam a produção e a comercialização de maconha no país, 
além de reivindicações judiciais por parte de pais de crianças portadoras de síndromes raras associadas a epilepsias de difícil controle, que têm se beneficiado do óleo de maconha, rico em Canabidiol (CBD). KIEPPER e ESHER (2014, p. 2).

No ano de 2015 tem-se um grande marco para os militantes da causa medicinal da maconha, o componente canabidiol - CDB é retirado da lista de substâncias proscritas da ANVISA. Desta forma, passou a integrar a lista $\mathrm{C} 1$ da Portaria nº. 344/98, que define os controles e proibições de substâncias no país. Tal decisão infere na viabilização da importação dos extratos padronizados produzidos por indústrias farmacêuticas internacionais para tratar de casos graves da doença. Frisase que a legalização da maconha para fins medicinais também tem o apoio de muitos médicos brasileiros, uma figura importante neste meio é o médico ElisaldoCarlini do Centro Brasileiro de Informações sobre Drogas Psicotrópicas - Cebrid - que alega os benefícios da planta para cura de várias doenças e redução dos efeitos causados pelo uso de medicamentos contra o câncer (SILVA et al, 2017, p. 27).

Em 2016 a ANVISA autoriza a manipulação e prescrição de medicamento à base de cannabis, tanto para produtos registrados pela Agência como para os que forem importados em caráter de excepcionalidade. A droga já é aprovada em 28 países, dentre eles estão: Estados Unidos, Canadá, Alemanha, Dinamarca, Suécia, Suíça e Israel, onde é conhecido por Sativex.

O momento de regozijo para todos que anseiam e buscam a legalização foi dado em janeiro deste ano (2017), quando a ANVISA registrou o primeiro medicamento a base de cannabis no Brasil, cujo nome comercial é Mevatyl - o medicamento contém tetraidrocanabinol (THC) em concentração de 27 mg/mL e canabidiol (CBD) em concentração de $25 \mathrm{mg} / \mathrm{mL}$. Em seguida a tal fato, ocorreu no mês de maio a inclusão da cannabis sativa na Lista Completa das Denominações Comuns Brasileiras (DCB) sob a configuração de planta medicinal, em atenção à Resolução da Diretoria Colegiada (RDC) No 156, de 5 de maio de 2017, publicada no Diário Oficial da União em 8 de maio de 2017. Frisa-se que a medida tomada pela ANVISA não permite o uso medicinal da planta em qualquer situação tem apenas o caráter formalizador do componente para possíveis registros de medicamentos, todavia, não se deixa de considerar um grande avanço para uma conjuntura anterior de criminalização e preconceitos.

Neste diapasão verifica-se a discrepância entre os anos iniciais de inserção da planta da maconha em território brasileiro, para com os tempos atuais. A busca por conscientização associada à luta de famílias e de ativistas que reconhecem desde cedo a importância de se legalizar a 
maconha para fins medicinais provocou mudanças, atribuindo sensibilização e ganhando cada vez mais o apoio da população. Vê-se com isso a ressignificação do passado para a construção de uma nova memória, esta agora associada a avanços e liberdade, reconhecendo que a maconha possui benefícios incomparáveis e que a sua legalização é uma questão necessária e resgatando a sua utilidade cultural de antigamente.

\section{Considerações Finais}

Tendo em vista a pauta trazida neste artigo fica claro que a criminalização da maconha possui raízes históricas profundas que alcançam nossa época do descobrimento territorial, e suas ramificações se estendem até os dias atuais. Isto posto, extrai-se o caráter preconceituoso nos discursos proibicionista haja vista a inserção da cannabis em terras brasileiras estar associada a vinda dos escravos para o Brasil, uma vez que o seu consumo pela comunidade negra era inserido dentro de um contexto cultural. Corroborando neste entendimento as expressões utilizadas à época, tais como: Fumo de negro; Pito do Pango e Fumo de Angola faziam alusão a tal grupo social.

Todavia o tempo passa, a abolição da escravatura é assinada e o panorama muda, estendendo a prática a todo indivíduo que dela fizesse uso, entretanto as referenciações à comunidade negra não deixaram de existir. Outrossim, todos os benefícios medicinais e usuais que à planta são ofertados e que era de conhecimento de todos. Frente a isso se compreende a memória de sofrimento, marginalização e repressão construída e que vem a ser ressignificada mais a frente.

Nesta perspectiva memorialística conseguimos compreender as rupturas paradigmáticas que circundam esta temática, pois verificamos novas reflexões e posicionamentos no século XXI voltadas a uma sensibilização para suas funções medicinais, e toda uma gama de doenças que podem ser tratadas com o uso da planta, a despeito, as convulsões, doença de Crohn e depressão. Os avanços jurídicos são aprovados em atenção a pressões sociais e pacientes cada vez mais cansados do sofrimento diário que os assolam. Graças a tal fator atualmente, se tornou mais fácil adquirir medicamentos à base de compostos da cannabis, diferentemente do ano de 2013, por exemplo.

Há de se considerar que ainda é uma pequena fatia da população brasileira que adere e milita a favor da causa, entretanto ano a ano este quadro vem sendo modificado, e se compararmos a conjuntura de 1830, por exemplo, já avançamos significativamente em tal aspecto, o que se visualiza nos atos de reconhecimento da cannabis como planta medicinal e a retirada do canabidiol da lista de substâncias proscritas da ANVISA.

O direito à vida, assim como à dignidade da pessoa humana são princípios presentes em nossa carta magna, e neste viés coloca-se que a 
regulamentação para uso medicinal da cannabis é uma questão urgente e necessária para se dar um passo para a reformulação de nossas políticas voltadas às drogas, assim como garantir a saúde em seu gozo pleno a pacientes acometidos de enfermidades. Neste limiar, reavaliando o teor e necessidade de tais normas, da forma que estão dispostas, estaremos retornando ao tempo para repensar, representar e ressignificar "com imagens e ideias de hoje, as experiências do passado" (BOSI, 1994, p.55). E desta forma, passaremos a compreender melhor a conjuntura cultural de utilização da cannabis nos tempos mais remotos. Descriminalizar não é sinônimo de libertinar.

\section{Referências}

AMUY, Liliane Maria Prado et al. Alei anti-tóxicos (no 6.368/76): os critérios científicos utilizados em sua elaboração e a exclusão do álcool . 2005. Dissertação (Mestrado em História da Ciência). 104f. Programa de Estudos de Pós-Graduação em História da Ciência. Pontifícia Universidade Católica de São Paulo, 2005.

AZEVEDO NETTO, C. X. de. Informações e Memória: as relações na pesquisa. História em Reflexão,Dourados, v. 1, n. 2, p. 1 - 20, jul./dez. 2007.

BAUMAN, Zygmunt. Modernidade líquida. Tradução: Plínio Dentzien. Rio de Janeiro: Jorge Zahar, 2001.

BARROS, J. D. História e memória: uma relação na confluência entre tempo e espaço. Mouseion. [S.I.],v. 3, n. 5, p. 35-67, jan./jul. 2009.

BARROS, André; PERES, Marta. Proibição da maconha no Brasil e suas raízes históricas escravocratas. Periferia.[S.I.],v. 3, n. 2, 2012.

BESSA, Marco Antônio. Contribuição à discussão sobre a legalização de drogas. Ciência \& Saúde Coletiva. [S.I.],v. 15, n. 3, p. 632-636, 2010.

BOSI, E. Memória e sociedade: lembranças de velhos. São Paulo: Cia. das Letras, 1994.

CANDAU, J. Memória e identidade. São Paulo: Contexto, 2016.

DÓRIA, José Rodrigues da Costa. Os fumadores de maconha: efeitos e males do vício.In:MINISTÉRIO DA SAÚDE, SERVIÇO NACIONAL DE EDUCAÇÃO SANITÁRIA, Maconha:coletânea de trabalhos brasileiros, 2. ed., Rio de Janeiro: Oficinas Gráficas do IBGE, 1958. 
DIEHL, A. A. Cultura historiográfica: memória, identidade e representação. São Paulo: EDUSC, 2002.

GRINSPOON, Lester. History of cannabis as a medicine. DEA statement, prepared for DEA Administrative Law Judge hearing. RetrievedSeptember, v. 24, p. 2013, 2005.

G1. Anvisa inclui Cannabis sativa em lista de plantas medicinais. [S.l.]: G1, 2017. Disponível em: https://g1.globo.com/bemestar/noticia/anvisainclui-cannabis-sativa-em-lista-de-plantas-medicinais.ghtml. Acesso em 30 ago. 2017.

IMPRENSA, Notícias STF: STF Libera "marcha da maconha". Portal STF. Publicado em: Quarta-feira, 15 de junho de 2011. Disponível em: http://www.stf.jus.br/portal/cms/verNoticiaDetalhe.asp?idConteudo $=1821$ 24. Acesso em: 03 set. 2017.

ISRAEL-PINTO, ALEXANDRE. O uso de substâncias psicoativas: história,aprendizagem e autogoverno. 2012. Dissertação (Mestrado em Psicologia). - Universidade Estadual de Maringá, Maringá, 2012. Disponível em: http://www.ppi.uem.br/arquivos-para-links/teses-edissertacoes/2012/alexandre. Acesso em: 03 set. 2017.

JESUS, Antônio Carlos Justo de et al. Legalização da maconha para fins medicinais. Revista do Curso de Direito da Universidade Braz Cubas.[S.I.], v. 1, n. $1,2017$.

KARAM, Maria Lucia. Proibição às drogas e violação a direitos fundamentais. Rio de Janeiro: [s.n.], 2013. p. 580-595..

KARAM, Maria Lucia. Proibições, riscos, danos e enganos:as drogas tornadas ilícitas. V. 3. Rio de Janeiro: Lumen Juris, 2009.

KIEPPER, André; ESHER, Ângela. A regulação da maconha no Senado Federal: uma pauta da Saúde Pública no Brasil. Cad. Saúde Pública. [S. l. ]v. 30, n. 8, p. 1-3, 2014.

KORYTOWSKI, Ivo. Quando e por que a maconha foi proibida no Brasil?[S.I. : s.n.],2016. Disponível em:

http://sopanomel.blogspot.com.br/2016/11/quando-foi-proibidamaconha-no-brasil.html. Acesso em 13 set. 2017.

LARANJEIRA, Ronaldo. Legalização de drogas e a saúde pública.Ciênc. saúde coletiva. Rio de Janeiro, v. 15, n. 3, p. 621-631, 2010. Disponível em: http://www.scielo.br/scielo.php?script =sci arttext\&pid=S1413$\underline{81232010000300002 \& \mathrm{nng}=e n \& n r m=i s o}$. Acesso em12 Set. 2017. 
LOUREIRO, Maria Lucia de Niemeyer Matheus.; AZEVEDO NEITO, Carlos Xavier; CASCARDO, Ana Beatriz Soares. Memória e cultura material: objetos, palavras e representações. In: Encontro Nacional de Pesquisa em Ciência da Informação, 15. 2014, Belo Horizonte. Anais... Belo Horizonte, 2014. Disponível em:

http://enancib2014.eci.ufmg.br/documentos/anais/anais-gt10. Acesso: 23 jan. 2015.

MONTEIRO, Marcelo. Uso medicinal da maconha no Brasil fica mais próximo.Zero Hora. Porto Alegre, maio 2014. Disponível em: http://m.zerohora.com.br/288/vida-e-estilo/4503232/uso-medicinal-damaconha-no-brasil-fica-mais-proximo. Acesso em: 10 set. 2017.

POLLAK, Michael. Memória e identidade social. Estudos Históricos. Rio de Janeiro, v. 5, n.10, 1992.

SAAD, Luísa Gonçalves. "Fumo de negro":a criminalização da maconha no Brasil (c. 1890-1932). 2013. Dissertação (Mestrado em História) Universidade Federal da Bahia, Salvador,2013. Disponível em: https://repositorio.ufba.br/ri/bitstream/ri/13691/1/DISSERTA\%c3\%87\%c 3\%830\%20LUISA\%20SAAD.pdf. Acesso em 10 set. 2017.

SILVA, Samuel Pereira da et al. descriminalização ou legalização do uso da maconha? e os projetos de lei sobre a maconha descriminalizar ou legalizar? Caderno de Graduação-Humanas e Sociais-FACIPE.[S.I.], v. 3, n. 1, p. 21-34, 2017.

SILVA, L. E. F. da; OLIVEIRA, B. J.F. de. Mnemosyneinfor-comunicativa: a possibilidade axiomática de construção de um conceito de memória para a Ciência da Informação. Inf. \& Soc.: Est., João Pessoa, v.24, n.1, p. 135143, jan./abr. 2014.

SUPREMO TRIBUNAL FEDERAL.STF Libera "marcha da maconha". Notícias STF. Brasília, DF, 15 jun. de 2011. Disponível em: http://www.stf.jus.br/portal/cms/verNoticiaDetalhe.asp?idConteudo $=1821$ 24. Acesso em: 03 set. 2017.

TRIGUEIRO, Pedro. Entorpecente e crime: apontamentos sobre a proibição da maconhano Brasil. Publicado em 26 de junho de 2015 por Revista Berro. Disponível em:

http://revistaberro.com/author/revistaberro/page/21/. Acesso em 13 set. 2017. 